\title{
O retorno de Marx em tempos neoliberais: sobre a ontologia e a política
}

\author{
The return of Marx in neoliberal times: on ontology and politics \\ Carlos Frederico Bernardo LOUREIRO* \\ José Garajau da SILVA NETO**
}

\begin{abstract}
Resumo: Os debates atuais que envolvem as crises cíclicas do capitalismo deixam claro existir uma dificuldade de aceitação a qualquer forma de crítica que aponte aos fundamentos do sistema, enquanto totalidade social historicamente determinada. Nosso objetivo, no presente ensaio teórico, é o de reafirmar o marxismo como método ontológico e teoria social de análise crítica do capital e de sua forma social. Reforçamos a tese de que é preciso retornar a Marx, na compreensão da totalidade social concreta, das múltiplas determinações que configuram a unidade do diverso em uma sociedade de classes, em suas contradições, diante da necessidade de se produzir a superação do sociometabolismo do capital.
\end{abstract}

Palavras-chave: Marx. Pós-modernidade. Ontologia. Liberdade.

\begin{abstract}
The current debates around capitalism's cyclical crises make clear that there is a difficulty in accepting any form of criticism that points to the core principles of the system, as an historically determined social totality. The goal of this theoretical essay is to reaffirm Marxism as an ontological methodology and a critical social theory for the analysis of capital and its social form. It reinforces the thesis that it is necessary to return to Marx, within his understanding of the concrete social totality and the multiple determinations that configure the unity of the diverse in a class-based society, with all its contradictions, in the face of the necessity of overcoming the socio-metabolism of capital.
\end{abstract}

Key words: Marx. Post-modernity. Ontology. Freedom.

Submetido em: 29/12/2017. Revisado em: 19/2/2018. Aceito em: 28/2/2018.

\section{Introdução}

Os debates atuais que envolvem as crises cíclicas do capitalismo dependente (FERNANDES, 1973 e 1975), deixam claro haver uma dificuldade de aceitação a qualquer forma de crítica que aponte aos fundamentos do sistema, enquanto totalidade social historicamente determinada. Isso porque, de maneira geral, a estrutura discursiva dominante faz com que se naturalize o binarismo moderno-atrasado, e a referência de desenvolvimento nos coloque sempre em uma posição de atraso. Além do fato de o capitalismo ter se posto como resultado e solução dos conflitos vividos no último século, o tempo de batalha ideológica pareceu ter chegado a um fim na década de 1990 com o encerramento da Guerra Fria.

\footnotetext{
Ecologista. Doutor em Serviço Social. Professor Doutor Associado da Faculdade de Educação da Universidade Federal do Rio de Janeiro (UFRJ) nos Programas de Pós Graduação em Educação (PPGE) e em Psicossociologia de Comunidades e Ecologia Social (EICOS). (UFRJ, Rio de Janeiro, Brasil). Av. Venceslau Braz, 7 1, Botafogo, Campus da UFRJ, Praia Vermelha, Rio de Janeiro (RJ), CEP 22290-140. Pesquisador do CNPq. E-mail: <fredericoloureiro89@gmail.com>. ORC ID: <https://orcid.org/oooo-0003-4640-6455>. ** Economista. Doutorando do Programa de Psicossociologia de Comunidades e Ecologia Social pela Universidade Federal do Rio de Janeiro. (UFRJ, Rio de Janeiro, Brasil). Av. Venceslau Braz, 7 1, Botafogo, Campus da UFRJ, Praia Vermelha, Rio de Janeiro (RJ), CEP 22290-140. Bolsista CAPES. E-mail: <znt.znt@gmail.com>. ORC ID: <https://orcid.org/oooo-ooo3-2131-8811>.
} 
É senso comum a narrativa que associa erroneamente as tentativas malogradas de uma possível saída anticapitalista a Marx. Apesar de compreendermos as diferenças contextuais do fim do século XIX e o início do século XXI, pensamos que as categorias desenvolvidas pelo autor de referência nas lutas antissistêmicas, na leitura dominante, sofreram uma inversão de propósito, de modo a trazer consigo agora, ao invés de um ideário de emancipação, um conjunto de vínculos com o anacronismo, totalitarismo e a ditadura, diametralmente opostos ao que representa o nosso sistema de relações sociais como expresso pelos seus think tanks: a forma ótima e última da liberdade e da democracia. Mais especificamente, as associações teóricas e práticas feitas ao marxismo no século XX passaram a, ironicamente, servir como uma arma de autodestruição. Sobre isso, Netto (2014) diz que:

[...] a mais óbvia grosseira resultante desse consórcio entre epistemologia e ideologia (ambas em sentido estrito) a serviço da ordem é a negação da categoria - ontológica e teórico - metodológica de totalidade, central no pensamento de Marx, por via do estabelecimento de uma relação causal entre ela e o que liberais e conservadores denominam 'totalitarismo' (NETTO, 2014, p. 3).

Essa argumentação anti-Marx e as lacunas conceituais daí derivadas são de nosso interesse. Isso porque nosso objetivo, no presente ensaio teórico, é o de reafirmar o marxismo como método ontológico e teoria social de análise crítica (CHASIN, 2009) do capital (enquanto relação social fundada em expropriações e geração de mais-valor) e de sua forma social (a sociedade capitalista). Mais adiante, discorreremos mais profundamente sobre o que subjaz essa demonização do método. No entanto, ressaltamos que tais inversões interpretativas são comuns nas próprias esquerdas, perdendo o potencial existente nessa perspectiva ontometodológica e epistêmico-política que foi capaz de tocar o cerne do sistema de produção vigente com um arsenal argumentativo à altura de seu poder. Ademais, a crise de legitimidade vivida em nossos tempos só corrobora com nosso diagnóstico de que por mais que não haja uma saída explícita, o capitalismo se encontra em uma encruzilhada, em função da intensidade de suas crises estruturais que colocam a possibilidade efetiva de um colapso ambiental e de extermínios violentos de vidas. $\mathrm{O}$ que reforça a tese de que é preciso retornar a Marx, na compreensão da totalidade social concreta, das múltiplas determinações que configuram a unidade do diverso em uma sociedade de classes, em suas contradições, diante da necessidade de se produzir a superação do sociometabolismo do capital (MÉSZÁROS, 2011).

\section{Delimitação conceitual}

Concordamos com Tonet na assertiva que "[...] a razão do mundo é a razão do mundo [...]" (TONET, 2013, p. 23), ou seja, o conhecimento de si de um mundo, de uma sociedade, é um espelhamento do seu processo de reprodução. Em termos do trabalho como ato histórico fundamental, o sociometabolismo do capital é estranho e alienado ao passo que, como afirmado por Marx nos Manuscritos Econômicos e Filosóficos (MARX, 20o8), as relações

sociais alienadas se dão na medida em que o indivíduo: a) é alienado de seu ser genérico, ao ponto que a propriedade privada fragmenta as relações humanas baseando o ser mesmo do homem em suas posses; b) é alienado do produto de seu trabalho, ao passo que a propriedade privada dos meios de produção dá ao detentor dos meios o resultado do trabalho de outro indivíduo; c) nesse sentido, o trabalhador é automaticamente alienado em relação a si mesmo, já que não reconhece no produto de seu trabalho algo representativo de sua própria

Argum., Vitória, v. 10, n. 2, p. 190-202, maio./ago. 2018. 
humanidade; d) como consequência, o indivíduo é alienado em relação ao seu semelhante, visto que a relação de apropriação e expropriação dos meios de produção traz consigo uma fragmentação essencial e, finalmente e) o sujeito é alienado em relação ao seu próprio trabalho, já que o objeto que produz não é de sua posse direta, não o representa como indivíduo peculiar que é em sociedade e, por isso, não o afirma como ser-em-si.

Utilizamos aqui a radicalidade do conceito de alienação ao colocá-lo como universal para estabelecer o que já vimos discorrendo: o sistema capitalista engendra relações sociais de subsunção formal dos sujeitos à sua mercantilização o que, por sua vez, impossibilita o estabelecimento de uma reprodução social com lastro no potencial humano, transferindo o produto do trabalho humano em valor excedente para o capital. Nesse sentido, o caráter cla ssista intrínseco ao capitalismo formaliza verticalmente a propriedade dos meios de produção a poucos indivíduos e, com isso, a grande maioria da população é deixada a esmo das margens de lucro e dos baixos salários em condições que beiram à subsistência, ou a formas variadas de expropriações (das terras/territórios, conhecimentos, saberes etc.) necessárias à acumulação de capital e à reprodução social. Cabe ressaltar ainda que, em última análise, o acesso aos salários é restrito a uma parcela de indivíduos que passam a ser os únicos capazes de desfrutar da liberdade no mercado, ao passo que essa liberdade, paradoxalmente, não representa a emancipação ontológica, ou seja, a emancipação efetiva do ser.

Sem embargo, entendemos que a raiz da crise das relações sociais se encontra na impossibilidade estrutural da emancipação humana em um cenário no qual reinam as relações sociais alienadas e a propriedade privada como fundamento da reprodução social. Ou, em outras palavras, se os olhos de Marx não estavam míopes, dentro do capitalismo tudo pode existir, exceto a liberdade. Entendemos que o anti-marxismo emergiu como arma ideológica conveniente ao ideal de liberdade e democracia identificados em geral com a ordem capitalista, o que ao mesmo tempo vinha temperado com uma necessidade de se construir essa imagem de que valores como a liberdade e a democracia só podiam surgir dentro do capitalismo.

A essa altura, a derrocada não só das experiências socialistas no Oriente, bem como das buscas que fizeram emergir o pensamento crítico na década de 1970 como resultado não só do pós-guerra como também da lamentável incursão ianque no Vietnã, serviram como base para ainda capitular a intelectualidade da emergente social-democracia para a legitimação da derrota da práxis anti-hegemônica em nível absoluto (NETTO, 2012). Por isso, a fragilização da teoria e da práxis da esquerda ao longo de todo o século XX acabou por resultar em uma necessidade de minimizar a amplitude das lutas sociais, ao passo que cada vez mais se constatava o grau de dificuldade titânico que se erigia sobre qualquer luta anti-hegemônica efetiva. Nesse sentido, não é estranho que tenham se desenvolvido, em meio à atrofia dos movimentos trabalhistas, ramificações de processos de inserção social por parte de minorias étnicas, mulheres, negros, gays e etc ${ }^{1}$ - o que demonstra notadamente o grau de fragilização ideológica vivido por aqueles que compartilham do movimento crítico desde então. É mister que se estabeleça uma relação mais honesta com o marxismo, que seja adequada ao contexto atual do capitalismo, de modo a ainda se mostrar como instrumental teórico-metodológico

\footnotetext{
1 Não deixaremos de enfatizar a importância fundamental de toda e qualquer luta por liberdade no âmbito da particularidade. Ademais, nossa preocupação é abertamente a de que tais movimentos tragam, em termo universal, uma tendência ao separatismo e à segregação quando dizem respeito a unificarem -se diante da causa que consideramos fundamental: a batalha anti-hegemônica contra o capital.
}

Argum., Vitória, v. 10, n. 2, p. 190-202, maio./ago. 2018. 
válido na crítica ao sistema por meio da revalidação e reconsideração de suas categorias e também do esclarecimento das falhas conceituais trazidas junto à sua história. Para tanto, nosso objeto de reflexão se dará justamente na categoria central da teoria marxiana que se coloca atemporal (e não anacrônica, como preconizam os think tanks liberais) na explicitação das mazelas do capitalismo: a alienação.

\section{A alienação e sua contemporaneidade}

Apesar da complexa rede de fatores que envolvem a deflagração de crises no âmbito do cotidiano, compreendemos que seu fundamento último seja ligado a lacunas sistêmicas estruturais que se encontram na relação entre os indivíduos e a produção social. No que diz respeito à atualidade, a internacionalização da economia trouxe uma dimensão qualitativa à divisão internacional do trabalho que desponta abruptamente no formato distributivo da produção mundial. Por essa via, os conflitos que se manifestam cotidianamente nada mais são do que reflexos da forma tomada pelo mundo do trabalho, já que é justamente no âmbito da produção que se encontra o cerne dos conflitos que definem a dimensão nociva de nosso sistema econômico. Aos trabalhadores é exposta uma interação com a produção que os desumanizam absolutamente: uma crise sistêmica engendra, por sua vez, uma crise individual.

Sem embargo, a visão de uma natureza humana como transfiguração de seu sistema produtivo e distributivo não pode ser vista unilateralmente. Não devemos rejeitar a formação social e histórica simplesmente sob um truísmo construído como uma ideologia sólida. Assim, para se justificar a natureza humana com bases fixas no egoísmo e na competitividade, devemos explorar acima de tudo os seus pressupostos, colocando-os em xeque. $\mathrm{O}$ discurso da liberdade dentro do capitalismo como palavra-chave é a grande questão a ser desvelada para se buscar uma crítica anti-hegemônica.

Entendemos que a alienação perpassa (obviamente) a própria ideia de liberdade, não fosse o caso, esse debate seria completamente inócuo. Como enfatizamos por meio de Marx, o trabalho é considerado tanto em sua acepção geral - como atividade produtiva ontocriativa, a determinação ontológica fundamental da humanidade - como em sua acepção particular, na forma da divisão do trabalho capitalista. É nesta última forma, a atividade estruturada em moldes capitalistas, ou seja, na qual as relações de trabalho são permeadas pela propriedade privada, que o "[...] trabalho é a base de toda a alienação" (MESZÁROS, 20o6, p. 78). Ao passo que a premissa básica do capitalismo neoliberal é a liberdade aliada à democracia, tem-se um contrassenso no que diz respeito ao que se evidencia na sociedade de classes: como é possível a emergência da liberdade efetiva quando aliada à mercantilização inevitável da vida? Seria possível aliar a venda imperativa da força de trabalho a alguma forma de emancipação? Para nós a questão responde a si mesma em seu nítido antagonismo.

Em nossa análise, a produção material está para o indivíduo como gênese ontológica, como processo de intercâmbio essencial entre o sujeito e a natureza. A atividade produtiva aparece nessa relação e também pode, através desse intermédio, agir de maneira a conduzir de forma humana o processo de modo que sob um aspecto, "[...] a natureza [medeie] a si mesma com a natureza; e, sob o segundo aspecto ontológico - em virtude de que a atividade produtiva é inerentemente atividade social - o homem [medeie] a si mesmo com o homem" (MESZÁROS, 2006, p. 81). 
A socialização é um aspecto próprio do indivíduo. A formação humana se dá em sociedade e essa sociedade se edifica em seu desenvolvimento histórico, ao passo que este desenvolvimento tem como base o fato de que o sistema produtivo, e por conseguinte a divisão do trabalho, são aspectos determinantes na gênese desse ser social.

Se seguirmos esse raciocínio, conseguiremos compreender que o trabalho na condição pósmoderna $a^{2}$ é norteador da construção socioeconômica que satisfaz a forma atual do capital. Em outras palavras, é através da acepção do trabalho contemporâneo que compreendemos efetivamente essas relações. Nas palavras de Iamamoto, "[...] o trabalho em fluxo é um componente subjetivo do processo de produção porquanto componente da humanidade do indivíduo em processo de realização [...]" (IAMAMOTO, 2001, p. 71) e, assim sendo, nosso diagnóstico não poderia ser mais acertado, já que é exatamente a realização do indivíduo como mercadoria, como ente privado que busca a satisfação de suas necessidades única e exclusivamente através da venda de sua força de trabalho, que descrevem a situação dos sujeitos no capitalismo.

A noção de esfera privada condizente com a história da política moderna, traduzida no pensamento liberal, nada mais é do que a constatação que as relações sociais se determinam pela antítese de interesses privados, o que em última instância significa que "[...] a ideia de que cada um, perseguindo seu próprio interesse privado, contribui para a efetivação do interesse geral, como unilateralidade dos interesses egoístas, [é o] dogma [...] da economia de mercado" (IAMAMOTO, 2001, p. 59). Nesse caso, o dogma que desconsidera um fato fundamental; o de que o próprio interesse privado já é socialmente determinado, por só poder ser atingido dentro de relações inseridas em um contexto social específico, portanto, determinado por elas, ultrapassando o indivíduo como seu fundamento primeiro. Enfatizamos que, por mais que a noção de indivíduo tenha se desenvolvido de fato dentro de um contexto que culminou em uma sociedade de mercado na qual a liberdade foi desde então associada à possibilidade do descolamento de relações pré-mercantis quase escravocratas, não se pode negar que tal liberdade de venda de trabalho não possui uma relação direta com a emancipação real do sujeito. No que diz respeito à alienação, ao contrário, tal estrutura só contribui para o exato oposto da liberdade. Mesmo assim, entendemos igualmente ter se tratado de um processo necessário para que chegássemos aonde estamos, no contexto social que permite o olhar crítico da mercantilização dos indivíduos diante da possibilidade de uma verdadeira emancipação que passe à busca da expressão individual de cada sujeito em sua plena efetividade.

Levando em consideração os pressupostos básicos, mesmo mencionados en passant, que se estendem à análise da teoria política liberal, não é difícil que cheguemos à conclusão de que no sistema capitalista a liberdade é fruto de uma relação intransponível de dependência da potência econômica. Por outro lado, essa potência é derivada de relações sociais claramente desiguais, ao passo que empreender um ponto de partida semelhante a todos os indivíduos soa como um absurdo prático indecoroso. $\mathrm{O}$ mais impressionante é que esse discurso vem se tornando predominante nos últimos anos, com a repetição dos ciclos econômicos que, como

\footnotetext{
2 Aqui nos referimos positivamenteà obra de David Harvey (1996), A Condição Pós-Moderna, na qual o autor implementa uma visão importantíssima dos novos modos de organização econômica quando relacion ados à organização territorial e, consequentemente e tão logo, às relações de trabalho.
}

Argum., Vitória, v. 10, n. 2, p. 190-202, maio./ago. 2018. 
já descritos por nós nas palavras de Marx, são sempre constituídos por períodos de crise nos quais preponderam os apontamentos acerca da ingerência e ineficácia dos agentes do Estado, ou até mesmo da própria estrutura do Estado em si no que diz respeito a permitir de fato a liberdade do mercado. Por essa via, o mecanismo de transferência de responsabilidade das mazelas sistêmicas para o próprio Estado, ao passo que as mazelas individuais são igualmente transferidas à incapacidade de inserção dos indivíduos particulares na economia de mercado, é uma forma cínica de encobrir a trama de relações sociais desiguais.

Para o que aqui chamaremos de capitalismo da pós-modernidade tal ideia é bastante conveniente, já que o aspecto disjuntivo da atual estrutura social favorece a impressão de que apenas diversos indivíduos particulares, e logo, a somatória de suas vontades (egoístas, individualistas e competitivas), são suficientes para definir a essência humana e, para além, a sociedade como tal. O duplo sentido problemático dessa assertiva assenta-se no fato de que, partindo desse raciocínio, institui-se primeiramente como condição sine qua non o indivíduo formado socialmente no capitalismo como sujeito absoluto, totalmente responsável por seu sucesso ou fracasso e, em segundo lugar, que o capitalismo é igualmente o sistema absoluto por ser o único que permite a efetivação dessa natureza humana tida em sua forma mais pura. Mais ainda, tal discurso se estende obviamente à esfera do equilíbrio do mercado, já que, como mercadorias declaradas, os indivíduos são postos diante de impedimentos externos (por parte do aparato burocrático do Estado) o qual os impede de empreender de forma suficientemente livre ao ponto de conseguirem dar suas contribuições para o aquecimento econômico, leia-se, a produção e a circulação de mercadorias. Não obstante, em se tratando da ideia fixa de que um sistema econômico já representa integralmente o único resultado possível da sociedade, poderíamos concluir que de fato chegamos ao fim da história humana, posto que, de maneira geral, atingimos o único ápice legítimo de seu desenvolvimento como tal.

Para nós, trata-se de um ponto de vista deveras frágil, tendo em vista que sem muita dificuldade podemos constatar que não há o que configure tal essência humana para justificar tal fim possível. A história da atividade humana se mostra como uma história de sua autocriação, portanto, a formação da essência humana é radicalmente e acima de tudo social e histórica. Ao enfatizar o lugar do indivíduo ignorando essa sua formação, qualquer análise da sociedade torna-se débil, justamente por negar que essa individualidade se dá, se desenvolve e se exprime socialmente, logo, num tempo e espaço específicos. Em outras palavras, a subjetividade humana é histórica e socialmente situada; de fato até mesmo seus sentidos são construções históricas, como diz Marx ao explicar:

[...] [é] apenas pela riqueza objetivamente desdobrada da essência humana que a riqueza da sensibilidade humana subjetiva, que um ouvido musical, um olho para a beleza da forma, em suma as fruições humanas todas se tornam sentidos capazes, sentidos que se confirmam como forças essenciais humanas, em parte recémcultivados, em parte recém-engendrados (MARX, 2008, p. 92).

Sem embargo, o processo de humanização transpassa o reducionismo de um seguimento biológico e torna a dicotomia entre o que é subjetivo e o que é objetivo, ou ainda, o que é biológico e o que é social, estéril. O desenvolvimento humano é dado “[...] através do processo de objetivação que, para realizar-se, necessita que cada indivíduo se aproprie daquilo que foi objetivado pelas gerações que lhe antecederam” (MARX, 20o8, p. 50). Não nos cabe

Argum., Vitória, v. 10, n. 2, p. 190-202, maio./ago. 2018. 
no presente momento, no entanto, exemplificar em pormenores a constatação dessas palavras de Marx, até por que o serviço pródigo de György Lukács em sua obra seminal, A Ontologia do Ser Social (LUKÁCS, 2013), cumpriu, dentre outras, essa função. O autor húngaro debruçou-se sobre as então recém-descobertas obras do jovem Marx e, munido de uma sensibilidade sem igual, explorou os meandros da relação entre o indivíduo biológico e social. Nesse sentido, permitiu que se aprofundasse a teoria social marxiana para que chegássemos ao debate corrente, tão rejeitado pelas correntes pós-modernas, de que o indivíduo e a sociedade são um só corpo e os processos determinantes do todo da formação social não podem ser definidos pelas suas partes. Na verdade, arriscamos dizer que a história da teoria política moderna se sustenta sobre a tentativa de ora velar, ora tornar óbvio, que não é possível tratar o processo de formação social (universal) por meio de de análises que reduzam a formação social aos sujeitos individualmente (singulares). Em outras palavras, a história da teoria política contemporânea não pode ser vista sem seus conflitos imanentes; estes, por sua vez, estão sempre diretamente ligados ao desenvolvimento do conceito de indivíduo, mas como sua parte.

Vamos ainda mais adiante apostando que uma das razões pelas quais a chamada crise da pós- modernidade se dá é a de que o desenvolvimento das forças produtivas chega a um ponto no qual se torna inevitável o surgimento de uma necessidade de liberdade. E nesse lugar, o invólucro ideológico das classes dominantes, ou, em outros termos, o processo de alienação do trabalho, precisa ser levado a um nível radical para não permitir que a atual estrutura das relações sociais, que contém em si condições objetivas suficientes para engendrar a liberdade humana de maneira efetiva, torne tal objetivo inconveniente por não satisfazer os detentores do capital os quais, por sua vez e como única razão justificável, nutrem-se da alienação humana.

E não se trata aqui de fazer unicamente um Manifesto contra as conquistas positivas do modo de produção capitalista. Aliás, nenhuma crítica sensata o faria, afinal de contas, não há como negar as conquistas que uma lógica de produção em massa pode trazer. À medida que a lógica do descartável da obsolescência seja copartícipe dessa ampliação de potência produtiva, a febre do ouro da reprodução do valor enreda positivamente a possibilidade de satisfação das necessidades humanas básicas, deixando como ponto focal a pergunta do porquê ou o questionamento do lugar em que essa resolução se assenta, já que o resultado visto por nós é bem diferente de nossa constatação. Se libertar efetivamente o trabalhador é possível nas condições atuais, nosso fim só pode ser o de desnudar os únicos interesses a serem atendidos que impedem a realização da liberdade humana; para nós, esses interesses são diretamente relacionados à satisfação da reprodução do capital.

A história da constituição do próprio gênero humano se encontra expressa no desenvolvimento da sociedade e naquilo de que a subjetividade se apropria, a ponto de estabelecer-se $e$ universalizar-se como tal. "A relação entre objetivação e apropriação do gênero só é préexistente à atividade de cada indivíduo, mas não [à] atividade do conjunto dos indivíduos ao longo da história” (LUKÁCS, 2013, p. 54). Isso significa que os sujeitos têm contato justamente com aquilo que o gênero humano como um todo conseguiu atingir histórica e objetivamente. Nas palavras de Lukács:

Argum., Vitória, v. 10, n. 2, p. 190-202, maio./ago. 2018. 
[...] a contradição dialética entre desenvolvimento da capacidade e desenvolvimento da personalidade, ou seja, o estranhamento, jamais abrange [a] inteira totalidade do ser social do homem, mas, em contrapartida, ela nunca se deixará reduzir [...] a uma contraposição abstrata de subjetividade e objetividade, a uma contraposição de homem singular e sociedade, de individualidade e socialidade. Não há nenhum tipo de subjetividade que não seja social, nas raízes e determinações mais profundas do seu ser. A mais simples análise do ser do homem, do trabalho e da práxis mostra isso de modo irrefutável (LUKÁCS, 2013, p. 588).

Indo além dessa análise processual do que representa a humanização dos sujeitos em um caráter cognitivo e comportamental, passaremos para o segundo ponto crucial de nosso trabalho: o posicionamento acerca do caráter próprio da formação humana no capitalismo da pós-modernidade. Ao localizarmos o capitalismo sob a alcunha da pós-modernidade, partimos do pressuposto de que o debate acerca da liberdade e/ou emancipação humanas já passou por uma fase marcante no início do século XX culminando na Guerra Fria. Entendemos, acima de tudo, que essa nova leitura deve desvendar uma nova comunicação da teoria crítica, de forma a retomar, até onde possível, sua validade. Para tanto, a fim de desvendar o antagonismo do sistema de forma universal, apenas uma contraposição igualmente universal à altura poderá fazê-lo.

Com base no que acabamos de expor, entendemos o aspecto fugidio da pós-modernidade embasada na [cretinice] e na unilateralidade de compreender as relações sociais sob a posse. "O lugar de todos os sentidos físicos e espirituais passou a ser ocupado, portanto, pelo simples estranhamento de todos esses sentidos, pelo sentido do ter" (MARX, K, 2008, p. 108). Para nós, não poderia haver definição mais lúcida do fenômeno da disjunção social pretendi$d a$. A pós-modernidade traz para fora do sujeito uma riqueza que é sua de fato, que lhe é interior. Não há como conceber nem abstrativa tampouco objetivamente a emancipação ou a liberdade humanas diante desse formato de relações sociais. E é exatamente aí que entramos em um grande redemoinho: o desmantelamento da esquerda e a valorização do empoderamento particular de modo algum contribuem para que o processo de unificação, pelo menos ideologicamente, ocorra de modo a elevar, em termos de confronto, à ascensão desmedida de grupos ultraconservadores - os quais relembram os tempos das conquistas coloniais, esbravejando a pilhagem e o genocídio de populações, além da violência desmedida contra aqueles que não compartilham de suas ideias. Vemos uma grande perda de consistência e congruência no discurso anti-hegemônico ao passo que o processo de autorreconhecimento da opressão se torna obscurecido por um ganho de protagonismo particular de amplitude limitada. Ao mesmo tempo, tal fato não deixa de ser mais um combustível para que as lutas revolucionárias ganhem novo terreno fértil para se desenvolverem.

\section{Ideologia, trabalho e a pós-modernidade}

Nossa preocupação com o que é chamado de pós-modernidade visa explicitar a maneira como as mesmas relações de exploração sempre existentes dentro do capitalismo se adequaram a esse período histórico. Hoje, o trabalho humano não funciona como um processo de autorreconhecimento dos sujeitos. Ao invés disso, põe-se como referência contraditória de entendimento de sua individualidade, com a única leitura possível sendo a da constatação de um processo de degeneração social, já que o espectro existente de relações sociais é permeado pelo pressuposto da alienação universal. Esse modelo de sociedade desejado reduz os 
indivíduos às suas próprias mazelas na medida em que não há nenhum critério de responsabilização ou visão de universalidade social como único cerne possível da mudança da condição da espécie humana. Ao passo que a própria relação basal entre os indivíduos e a natureza é mediada por essas relações alienantes e que o movimento para tal contraponto é impedido em seu núcleo, torna-se cada vez mais difícil sequer buscar um arcabouço teórico que possa orientar uma práxis anti-hegemônica.

De todo modo, nossa intenção de maneira alguma é empreender um diagnóstico fatalista ou pessimista. Pelo contrário, pensamos que o entendimento das mazelas do capitalismo é o combustível que nos guia com otimismo em direção a conceber um modo produção através do qual as capacidades e as personalidades humanas possam ser desenvolvidas em sua plena efetividade.

Acreditamos que qualquer transformação deve ocorrer para suplantar os aspectos negativos os quais constituem o atual modelo, ao passo que seu veículo sejam seus aspectos positivos. E nesse lugar, numa cruzada anticapitalista, ainda assim precisamos reiterar "[...] o desenvolvimento das forças de trabalho [...] no sentido de que o tempo de trabalho socialmente necessário à reprodução do homem [...] [diminui] constantemente [...] [e] o peso econômico dos atos necessários à reprodução [...] [perdem] [dominância]" (LUKÁCS, 2013, p. 595). Por que razão? Justamente a de que a própria alienação ganha um caráter duplo: por um lado, temos relações sociais que engendram uma atividade produtiva estruturalmente alienante e, por outro, a liberação da sociedade em geral do tempo de trabalho necessário para reproduzir a vida humana. Neste último caso, vemos a liberação desse tempo de trabalho como veículo fundamental para comprovar o caráter contraditório dessa organização social. Como seria, então, possível? Qual impedimento real, no capitalismo, de se refazerem os trilhos da exploração rumo à liberdade? Devemos localizar o que impede o processo de emancipação e libertação de se efetivar, relembrando os aspectos de tensão fundamentais, lembrados por Lukács quando diz que:

[...] quanto mais desenvolvido for o aparato ideológico do capitalismo, tanto maior será a sua disposição de fixar mais firmemente tais formas de estranhamento nos homens singulares, ao passo que, para o movimento revolucionário dos trabalhadores, para o despertamento, a promoção e a maior organização possível do fator subjetivo, desmascarar o estranhamento enquanto estranhamento, a luta consciente contra ele, constitui um momento importante [...] da preparação para a revolução (LUKÁCS, 2013, p.625).

Esses dizeres de Lukács há pouco mais de meio século deixam claro que esse aparato ideológico constitui por um lado, a barreira e, por outro, o instrumento capaz de estabelecer no conflito a abertura a uma nova estrutura de relações sociais. Ao mesmo tempo, é igualmente claro desde os tempos do pós-guerra que o âmbito ideológico da estrutura social ganhou corpo e densidade com o poder implícito da bomba atômica.

Ao concordarmos que "[...] as relações burguesas de produção são a última forma antagônica [...] que provém das condições sociais de vida dos indivíduos [...]” (MARX, 2007, p. 48), reconhecemos as possíveis vias de mudança no absurdo da conjuntura, haja vista a crescente concentração dos poucos detentores dos meios de produção ao contrapasso da precarização das condições dos trabalhadores em geral. O caráter do vazio-subjetivo, da ideologia não-

Argum., Vitória, v. 10, n. 2, p. 190-202, maio./ago. 2018. 
ideológica que se pretende, caracteriza um sistema social de hegemonia do eu que não condiz com a realidade possível do sistema. As novas formas de organização produtiva que visam promover um sujeito empreendedor de si não encontram lastro na realidade do mercado. Nossa visão é a de que houve uma incorporação inconsciente por parte do próprio movimento dos trabalhadores no sentido de assumirem-se em um não-lugar de potência e protagonismo em suas posições como trabalhadores. Esse empreendedorismo do século XXI é a declaração do desmonte da classe trabalhadora que vem sendo articulado como processo estrutural desde os anos 8o, após a crise real do capitalismo fantástico do pós-guerra.

Para tanto, a tentativa de se reunificar a teoria crítica precisa de uma práxis revolucionária inclusiva, não no sentido fragmentário, mas sim de maneira que essas partes que podem constituir um todo crítico universal sejam capazes de superar em-si os limites, no espaçotempo, que a impede de se remontar. É exatamente por isso que acreditamos que a teoria crítica está viva, aberta e preparada para ceder o instrumental necessário à instituição de um direcionamento coerente no qual os sujeitos possam de fato passar a construir sua própria história. E, como Lukács, acreditamos que:

[...] a história do devir homem do homem, em que a sociedade se torna a expressão adequada do gênero, só pode chegar a um termo quando os dois pólos do ser social, o indivíduo e a sociedade, cessarem de agir de modo espontaneamente antagônico um sobre o outro: quando a reprodução da sociedade promover o ser homem do homem, quando o indivíduo se realizar conscientemente em sua vida individual como membro do gênero (LUKÁCS, 2013, p. 426).

E por mais que o atual tempo histórico manifeste uma natureza humana burlesca em uma existência risível, um antagonismo tão radical entre a capacidade e a manifestação da personalidade humanas contém em si inevitavelmente o seu contraponto. O papel da teoria crítica é o de explicitar o lugar de ser do ser, onde mais aparenta desencontro. Não obstante, a realização consciente da individualidade, a efetivação do gênero humano como tal é nossa referência fundamental.

Ademais, como seria possível atravessar os limites sociais à emancipação em um cenário ideológico que precisa da dissolução de qualquer senso de coesão universal e só considera o sujeito livre na sociedade de mercado?!

E por mais que o atual tempo histórico manifeste uma natureza humana burlesca em uma existência risível, um antagonismo tão radical entre a capacidade e a manifestação da personalidade humanas contém em si inevitavelmente o seu contraponto. O papel da teoria crítica é o de explicitar o lugar de ser do ser, onde mais aparenta desencontro. Não obstante, a realização consciente da individualidade, a efetivação do gênero humano como tal é nossa referência fundamental.

Ademais, como seria possível atravessar os limites sociais à emancipação em um cenário ideológico que precisa da dissolução de qualquer senso de coesão universal e só considera o sujeito livre na sociedade de mercado?!

Por essa via, a expressão desse rompimento universal dentro do pensamento crítico se põe no grande desafio de superar as relações de trabalho que permanecem amparadas ao lado da 
lógica de exploração humana. Essa expressão não está no primeiro plano das batalhas de afirmação identitária. Por isso o nosso apontamento crítico fundamental acerca da pósmodernidade: a multiplicidade do possível, no que diz respeito às lutas particulares, dilui o foco do caráter determinante de uma práxis revolucionária universal, criando uma série de barreiras sociais e institucionais à construção do grande encontro entre teoria e práxis críticas em uma metodologia que exponha a anatomia de nossa sociedade como instituída sob a égide da opressão.

Ao mesmo tempo, o caráter descentralizado e fugidio dos tempos pós-modernos dá combustível ao discurso liberal na assertiva que reduz a realização plena da subjetividade humana como mote da estrutura social na redução da liberdade ao triunfo da identidade, traduzidas aqui no desafio de se construir o grande encontro entre teoria e práxis críticas que exponha a anatomia de uma sociedade instituída sob a égide da opressão.

E essa é mais uma razão para elevarmos o pensamento de Marx ao status de fundamental como arcabouço metodológico, concordando que a relação entre a natureza humana e o egoísmo é a construção ontológica do sociometabolismo do próprio capital. Conceder qualquer tipo de natureza essencial a priori é o mesmo de se buscar, a-historicamente, a igualdade entre o sujeito como parte e o todo que o subsume. Como Meszáros (2006), acreditamos que este é um sujeito fictício, ao passo que a resultante desse empreendimento ideológico falacioso não passa de um transcendentalismo moral que não compreende a construção histórica (e por isso, real) do sujeito egoísta. Desse modo, apenas dentro do contexto específico de uma sociedade na qual as relações de trabalho são alienadas desde sua gênese é possível compreender que o pecado original da economia é a forma ótima (e tão transcendental quanto à efetividade do capital em engendrar a liberdade) de fundamentar a ideia de uma natureza humana egoísta.

Essa função de saída do reino do pecado através da manifestação de uma instância espiritual que liberta o indivíduo, na visão de Marx, não pode levá-lo a uma liberdade efetiva, já que o autor entende que "[...] um ser se considera primeiramente como independente tão logo se sustente sobre os próprios pés, e só se sustenta primeiramente sobre os próprios pés tão logo deva a sua existência a si mesmo" (MARX, 2008, p. 113). Dessa maneira, se a independência é precondição para a liberdade, não é possível nem do lado espiritual da religiosidade tampouco do lado animalesco da natureza humana liberal encontrarmos a liberdade humana efetiva. Em outras palavras, o indivíduo constrói o seu ser-por-si em-si, pois só deve a si mesmo. Meszáros (2008) entende que:

[...] o 'ser-por-si-mesmo da natureza e do homem' marxiano - o homem que não é a contrapartida animal de uma série de ideais morais abstratos - não é, por natureza, nem bom nem mau; nem benevolente, nem malevolente; nem altruísta nem egoísta; nem sublime nem bestial etc; mas simplesmente um ser natural cujo atributo é: a 'automediação'. Isso significa que ele pode fazer com que ele mesmo se torne o que é em qualquer momento dado - de acordo com as circunstâncias predominantes seja isso egoísta ou o contrário (MESZÁROS, 2008, p. 151).

Dessa maneira, põe-se a necessidade de um materialismo metodológico que elimina qualquer tipo de dualidade possível através da análise dialética e contextual dos fatos, por meio dos quais se formam os parâmetros orientadores de uma práxis social/humana. Não importa

Argum., Vitória, v. 10, n. 2, p. 190-202, maio./ago. 2018. 
à filosofia moral o lado que toma no extremo transcendente de ideal humano almejado, pois a rejeição de qualquer oposição possível à radicalidade imposta à natureza humana certamente levará a uma análise falha. Não obstante, um dos troféus da condição pós-moderna é justamente a criminalização da história e a ascensão de uma visão moralista de um sujeito naturalmente imoral de sociabilidade dubitável.

A proposta de Marx para fugirmos desse tipo de análise reducionista reafirma todo o seu legado, qual seja, o de que os sujeitos são acima de tudo naturais, sem nenhuma pintura preconcebida por nenhuma filosofia moral. Em outras palavras, a própria ideia do pecado original da economia passa como um absurdo teórico e prático, ao passo que só "[...] empurra os sujeitos a um estado primitivo imaginário [...]” (MARX, 2008, p. 80), ou seja, a um nãolugar na história, o que por si só é uma atribuição a priori e, logicamente, impossível.

\section{Referências}

CHASIN, J. Marx: estatuto ontológico, resolução metodológica. São Paulo: Boitempo, 2009.

FERNANDES, F. A revolução burguesa no Brasil: ensaio de interpretação sociológica. Rio de Janeiro: Zahar, 1975.

FERNANDES, F. Capitalismo dependente e classes sociais na América Latina. Rio de janeiro: Zahar, 1973.

HARVEY, D. Condição Pós-Moderna: uma pesquisa sobre as origens da mudança cultural. 6. ed. São Paulo: Loyola, 1996.

IAMAMOTO, M, V. Trabalho e indivíduo social: um estudo sobre a condição operária na agroindústria canavieira paulista. São Paulo: Cortez, 2001.

LUKÁCS, G. Ontologia do ser social. Vol. I e II. São Paulo: Boitempo, 2013.

MARX, K. Manuscritos econômico-filosóficos. São Paulo: Boitempo; 2A, 2008.

MARX, K. Contribuição à Crítica da Economia Política. Tradução de Florestan Fernandes. São Paulo: Expressão Popular, 2007.

MÉSZÁROS, I. Para além do capital: rumo a uma teoria da transição. São Paulo: Boitempo, 2011.

MESZÁROS, I. A educação para além do capital. 2. ed. São Paulo: Boitempo, 2008.

MESZÁROS, I. A teoria da alienação em Marx. 1930. Tradução Isa Tavares. São Paulo: Boitempo, 2006.

NETTO, J. P. Karl Marx, nosso contemporâneo. Marx e o Marxismo: Revista do NIEP-Marx, Niterói, v. 2, n. 2, p 13-26, maio. 2014. Disponível em:

<http://www.niepmarx.blog.br/revistadoniep/index.php/MM/article/view/41>. Acesso em:

17 nov. 2017.

Argum., Vitória, v. 10, n. 2, p. 190-202, maio./ago. 2018. 
TONET, I. Método científico: uma abordagem ontológica. São Paulo: Instituto Lukács, 2013.

Carlos Frederico Bernardo LOUREIRO Trabalhou na revisão crítica e na aprovação da versão a ser publicada.

Professor Associado da Faculdade de Educação da UFRJ nos Programas de Pós Graduação em Educação (PPGE) e em Psicossociologia de Comunidades e Ecologia Social (EICOS). Líder do Laboratório de Investigações em Educação, Ambiente e Sociedade (LIEAS), na UFRJ. Pesquisador do CNPq.

José Garajau da SILVA NETO Trabalhou na concepção, delineamento e análise.

Possui graduação em Ciências Econômicas pela Ufes (2011). Mestrado em filosofia pela Ufes (2015). Doutorando do Programa de Psicossociologia de Comunidades e Ecologia Social pela UFRJ. Membro do Laboratório de Investigações em Educação, Ambiente e Sociedade (LIEAS) da UFRJ.

Argum., Vitória, v. 10, n. 2, p. 190-202, maio./ago. 2018. 